\title{
Correction to: An implicit-explicit time discretization scheme for second-order semilinear wave equations with application to dynamic boundary conditions
}

\author{
Marlis Hochbruck $^{1}$ • Jan Leibold ${ }^{1}$
}

Published online: 22 March 2021

(c) The Author(s) 2021

\section{Correction to: Numerische Mathematik https://doi.org/10.1007/s00211-021-01184-w}

In the original publication of the article, the formula in lines 534-537 was set incorrectly.

Also, the co-author's name in the paper was misspelled (instead of Hochbuck, it should be Hochbruck).

The original article has been updated.

Publisher's Note Springer Nature remains neutral with regard to jurisdictional claims in published maps and institutional affiliations.

The original article can be found online at https://doi.org/10.1007/s00211-021-01184-w.

Jan Leibold

jan.leibold@kit.edu

Marlis Hochbruck

marlis.hochbruck@kit.edu

1 Institute for Applied and Numerical Mathematics, Karlsruhe Institute of Technologie,

76049 Karlsruhe, Germany 